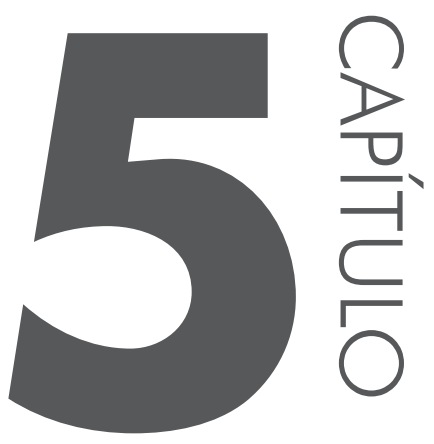

\title{
INFORMAÇÃO NUTRICIONAL DE REFEIÇÓES SERVIDAS PELO RESTAURANTE DA UNIVERSIDADE TECNOLÓGICA FEDERAL DO PARANÁ - CAMPUS LONDRINA
}

Bruna Mengue Fabiana Ribeiro Oribe

Lúcia Felicidade Dias Caroline Maria Calliari

\section{INTRODUC̣ÃO}

Os Restaurantes Universitários (RUs) têm a finalidade de preparar e distribuir ao corpo discente, docente e técnico administrativo das universidades refei- 
ções balanceadas, com qualidade nutricional e microbiológica, supervisionadas por nutricionistas especializados em alimentação coletiva e de acordo com as políticas de segurança alimentar e legislação higiênico-sanitária vigente (PROAD, 2013). O RU deve fornecer refeições nutricionalmente adequadas para os usuários, preparadas com base em estimativas devido à falta de informações exatas do perfil da clientela para avaliação do impacto nutricional dessa alimentação (FAUSTO et al., 2001).

As Unidades de Alimentação e Nutrição (UAN) que atendem à coletividades devem estar de acordo com as recomendações nutricionais diárias do usuário padrão (OLIVEIRA; GUAGLIANONI; DEMONTE, 2005) e o RU, enquanto UAN, deve seguir essas recomendações. A qualidade do alimento consumido é fundamental à saúde, e uma alimentação saudável deve conter todos os nutrientes, em proporções ideais, necessários para o bom funcionamento do organismo (BRASIL, 2006).

A Ingestão Diária Recomendada (IDR) sugere valores médios de nutrientes, considerando um adulto saudável, para satisfazer as necessidades nutricionais e energéticas dos indivíduos. Para que o consumo atenda à IDR, é fundamental saber a composição dos alimentos (GONDIM et al., 2005).

O Restaurante Universitário (RU) da Universidade Tecnológica Federal do Paraná - campus Londrina não possui informação nutricional dos alimentos oferecidos aos consumidores. Nesse contexto, a fim de fornecer a informação necessária para que o consumidor possa determinar a porção a ser ingerida, foi determinada a composição proximal dos alimentos mais frequentemente servidos pelo RU e elaborado material para divulgação dos resultados obtidos.

\section{A IMPORTÂNCIA DA ALIMENTAC̣ÃO SAUDÁVEL}

A alimentação considerada saudável é aquela que fornece todos os nutrientes, como água, carboidratos, proteínas, lipídios, vitaminas, fibras e minerais, em proporções e quantidades adequadas, promovendo saúde e permitindo o crescimento e desenvolvimento adequado às crianças e aos adolescentes, e peso adequado aos adultos e idosos (OLIVEIRA; SILVA, 2013).

Para ser considerada adequada e equilibrada, ou seja, para promover saúde e prevenir doenças, uma alimentação deve respeitar alguns requisitos: respeito e valorização de práticas alimentares culturais; acessibilidade física e financeira (uma alimentação saudável não deve ser onerosa, pois se baseia em alimentos regionais e in natura); sabor (uma alimentação saudável precisa ser saborosa e isso pode ser alcançado com alimentos menos refinados); variedade e cor, pois o consumo de vários tipos de alimentos fornece diferentes nutrientes, garantindo o atendimento das necessidades fisiológicas e o prazer à mesa; harmonia, no que se 
refere ao equilíbrio entre quantidade e qualidade; e, fundamentalmente, segurança sanitária (PINHEIRO, 2005).

Os hábitos alimentares são construídos de forma gradual e variam de pessoa para pessoa, sofrendo influência de valores culturais, sociais, afetivos, comportamentais e emocionais (OLIVEIRA; SILVA, 2013). Cada vez mais a ciência comprova que uma alimentação saudável é a base para a qualidade de vida, pois a origem e qualidade do que se consome é de fundamental importância para a saúde e para a possibilidade de aproveitar todas as fases da vida, da melhor forma possível, com saúde e disposição, e ter uma vida longa (BRASIL, 2006).

\subsection{Macronutrientes}

Os carboidratos são os componentes mais abundantes e amplamente distribuídos entre os alimentos. Atuam como gerador energia, adoçante natural, matéria-prima para produtos fermentados, são o principal ingrediente dos cereais, são responsáveis por propriedades reológicas da maioria dos alimentos de origem vegetal (polissacarídeo) e pela reação de escurecimento em muitos alimentos (PARK; ANTONIO, 2006).

Segundo o Ministério da Saúde (BRASIL, 2008), “os carboidratos são subdivididos em carboidratos complexos (amidos), carboidratos simples (açúcares simples ou livres) e fibras alimentares". A alimentação saudável deve incluir os carboidratos complexos em grande quantidade, atendendo de $45 \%$ a $65 \%$ do valor energético total, enquanto os simples são apenas fonte de energia e devem ser consumidos em quantidades reduzidas $(<10 \%$ do valor energético total).

Os grupos de alimentos, exceto as carnes, os óleos e o sal, possuem carboidratos em sua composição, diferindo na quantidade e no tipo de carboidrato. Quando essa quantidade é alta, o alimento é considerado fonte de carboidratos. Estes alimentos, em sua forma integral, devem ser a mais importante fonte de energia e o principal componente em grande parte das refeições, o equivalente a seis porções diárias (BRASIL, 2006).

Proteínas são heteropolímeros formados por unidades menores chamadas aminoácidos. São extremamente importantes na nutrição porque fornecem aminoácidos essenciais ao organismo. Os aminoácidos são chamados essenciais, pois o organismo não é capaz de sintetizá-los, na digestão há a quebra da cadeia de proteínas e os aminoácidos livres são absorvidos e usados na síntese de novas proteínas (PARK; ANTONIO, 2006).

As proteínas provenientes de alimentos de origem animal, tais como carne de todos os tipos, ovos, leite e derivados, são completas, ou seja, possuem todos os aminoácidos essenciais à manutenção e ao crescimento do corpo humano. Nos 
alimentos de origem vegetal não há todos os aminoácidos essenciais presentes, ou nas quantidades ideais. Porém, alguns alimentos combinados completam essas quantidades, como ocorre na combinação de arroz e feijão, que são uma fonte completa de proteínas quando na proporção de uma parte de feijão para duas de arroz (BRASIL, 2008). Essas combinações de cereais e leguminosas têm vantagens, pois são relativamente mais baratas que a carne, são integrais ou, em geral, altamente nutritivos e, ao contrário da carne, têm baixos teores de gorduras e teor muito baixo de gorduras saturadas. Recomenda-se o consumo diário de três porções de leite e derivados, uma porção de carnes, peixes ou ovos e uma porção de leguminosas, considerando a escolha de produtos que contenham menor teor de gordura (BRASIL, 2006).

O termo lipídio é utilizado para gorduras e substâncias gordurosas (PARK; ANTONIO, 2006). As gorduras são distintas em suas propriedades físicas e químicas, tornando-se mais ou menos benéficas para a saúde humana. Com base nessas características, as gorduras são classificadas em saturadas e insaturadas (BRASIL, 2006).

As gorduras saturadas aumentam o risco de dislipidemias e doenças cardíacas. As principais fontes são alimentos de origem animal, embora alguns óleos vegetais também sejam ricos nesse tipo de gordura. Ao contrário das gorduras saturadas, as insaturadas não causam problemas de saúde, exceto se consumidas em excesso. As gorduras insaturadas dividem-se em dois tipos, monoinsaturadas e poli-insaturadas.

A ingestão recomendada de ácidos graxos monoinsaturados para completar o percentual total recomendado para gorduras totais é calculada pela diferença em relação à soma dos demais [gordura total - (gordura saturada + gordura poli-insaturada + gordura trans)]. O consumo recomendado de ácidos graxos poli-insaturados é de $6 \%$ a $10 \%$ do total de energia diária e, para ácidos graxos trans, recomenda-se que constitua, no máximo, $1 \%$ do valor energético da alimentação diária, pois é um tipo de gordura obtida principalmente do processo de industrialização de alimentos, a partir da hidrogenação de óleos vegetais (VAZ et al., 2006).

A contribuição de gorduras e óleos, de todas as fontes, não deve ultrapassar os limites de $15 \%$ a $30 \%$ da energia total da alimentação diária, o total de gordura saturada não deve ultrapassar $10 \%$ do VET e o total de gordura trans consumida deve ser menor que $1 \%$ do valor energético total diário, o que representa no máximo $2 \mathrm{~g} /$ dia para uma dieta de $2.000 \mathrm{kcal}$. Recomenda-se o consumo máximo diário de uma porção de alimentos do grupo dos óleos e gorduras, dando preferência aos óleos vegetais, azeite e margarinas, sendo estes livres de ácidos graxos trans (BRASIL, 2006). 


\subsection{Ingestão diária recomendada}

De acordo com o Ministério da Saúde (Brasil, 2005), a Ingestão Diária Recomendada (IDR) é a quantidade de vitaminas, minerais e proteínas que deve ser consumida diariamente para que as necessidades nutricionais da maior parte dos indivíduos de uma população sadia sejam supridas. Para que o consumo de nutrientes atenda à IDR, é necessário o conhecimento das composições dos alimentos, uma vez que a composição é fundamental para avaliar e adequar a dieta (GONDIM et al., 2005).

Para manter a saúde e uma boa nutrição o consumo de energia deve ser adequado, de acordo com idade, sexo, prática de atividade física, presença de doenças, entre outros fatores de cada indivíduo. Considerando as variáveis, foi adotado um parâmetro brasileiro para a ingestão média diária de $2000 \mathrm{kcal}$ para um adulto saudável (BRASIL, 2008), estimativa da necessidade de energia média para uma população adulta e saudável. Em média, os homens brasileiros alcançam o equilíbrio energético com cerca de $2.400 \mathrm{kcal}$ por dia, enquanto as mulheres, com cerca de 1.800 ou $2.200 \mathrm{kcal}$ por dia. A média de $2.000 \mathrm{kcal}$ atende também às necessidades de energia das pessoas mais jovens (BRASIL, 2006).

Ainda de acordo com o Ministério da Saúde (BRASIL, 2008), “a informação nutricional deve conter a quantidade de energia que aquela porção contém e a quantidade em gramas ou miligramas dos seguintes nutrientes: carboidrato, proteína, gordura total, gordura saturada, gorduras trans, fibra alimentar e sódio para a rotulagem", não havendo obrigatoriedade desta informação para restaurantes.

A Tabela 5.1, criada pela Agência Nacional de Vigilância Sanitária - ANVISA (BRASIL, 2003), representa os macro e micronutrientes que devem estar presentes na rotulagem nutricional de alimentos embalados. Além disso, deve ser informado, na tabela, o Valor Diário de Referência, que indica a porcentagem de cada nutriente (em relação à ingestão diária recomendada) fornecida por uma porção do alimento, considerando um adulto saudável.

Tabela 5.1 Nutrientes de declaração obrigatória - Ingestão Diária Recomendada (IDR) para adultos saudáveis

\begin{tabular}{cc}
\hline Nutriente & \\
\hline Valor energético & 2000 kcal $-8400 \mathrm{~kJ}$ \\
Carboidratos & 300 gramas \\
Proteínas & 75 gramas \\
Gorduras totais & 55 gramas \\
Gorduras saturadas & 22 gramas \\
Fibra alimentar & 25 gramas \\
Sódio & 2400 miligramas \\
\hline
\end{tabular}

Fonte: Brasil (2003). 
Para o consumidor, é muito importante saber a quantidade de cada nutriente ou calorias em um determinado alimento. Além disso, é necessário saber se o valor representa um excesso ou é suficiente em relação aos parâmetros de necessidades nutricionais. Assim, nas tabelas de informação nutricional (BRASIL, 2003), ao lado da quantidade de calorias e de nutrientes, apresenta-se a informação do percentual de Valor Diário (\%VD), que informa quanto determinada porção de calorias ou nutriente supre em relação à IDR, considerando uma dieta de 2.000 kcal, conforme a Tabela 5.1 (BRASIL, 2006).

\subsection{Pirâmide alimentar}

A primeira pirâmide alimentar foi desenvolvida pelo Departamento de Agricultura dos Estados Unidos (United States Department of Agriculture - USDA), em 1992. Ela surgiu, pois acreditava-se que uma forma gráfica de distribuição dos alimentos resultaria em uma melhor compreensão por parte da população, ou seja, fazer com que haja o consumo de vários alimentos e em quantidade suficiente para que, juntos, componham uma dieta adequada nutricionalmente (PHILIPPI et al., 1999).

A pirâmide alimentar é descrita como um instrumento de orientação nutricional utilizado por profissionais com o objetivo de promover mudanças de hábitos alimentares, visando à saúde global do indivíduo e à prevenção de doenças (ACHTERBERG et al., $1994^{1}$ apud PHILIPPI et al., 1999).

Segundo Philippi et al. (1999), a pirâmide alimentar é constituída por quatro andares:

- $1^{\circ}$ Andar - alimentos energéticos. Correspondem a 50\% do que se deve comer e são ricos em carboidratos. Exemplos: pães, arroz, massas, batata, milho, mandioca, farinhas de mandioca, milho e trigo entre outros.

- $2^{\circ}$ Andar - alimentos reguladores, fonte de fibras, vitaminas e minerais, que têm a capacidade de regular o organismo humano. São as verduras, legumes e frutas.

- $3^{\mathbf{0}}$ Andar - construtores (proteínas). Exemplos: carnes brancas e vermelhas, ovos, leite e derivados e leguminosas.

- $4^{\circ}$ Andar - alimentos energéticos que devem ser consumidos em pequenas quantidades, pois são altamente energéticos e alguns desses alimentos contêm apenas calorias vazias (não possuem nutrientes saudáveis, além das calorias). São as gorduras (lipídios) e os açúcares (de mesa e doces em geral). É importante considerar que os diferentes tipos de gordura influenciam na saúde. As gorduras saturadas em excesso são maléficas à saúde, já as monossaturadas e poli-insaturadas trazem benefícios à saúde.

1 ACHTERBERG, G.; McDONNELL, E.; BAGBY, R. How to put the food guide into practice. Journal of American Dietetic Association, Chicago, v. 94, n. 9, p. 1030-1035, 1994. 
Os alimentos foram distribuídos na pirâmide em oito grupos (Figura 5.1), os quais foram compostos com alimentos semelhantes, e foi definido o número de porções diárias ideal para cada grupo (PHILIPPI et al., 1999):

1) Pães, cereais, raízes e tubérculos (pães, farinhas, massas, bolos, biscoitos, cereais matinais, arroz, feculentos e tubérculos: mínimo de cinco porções diárias, e nove no máximo);

2) Hortaliças (todas as verduras e legumes): mínimo de quatro porções diárias, e cinco no máximo;

3) Frutas: mínimo de três porções, e cinco no máximo;

4) Carnes (carne bovina e suína, aves, peixes, ovos, miúdos e vísceras): uma porção no mínimo, duas no máximo;

5) Leite (leites, queijos e iogurtes): três porções;

6) Leguminosas (feijão, soja, ervilha, grão de bico, fava, amendoim): uma porção;

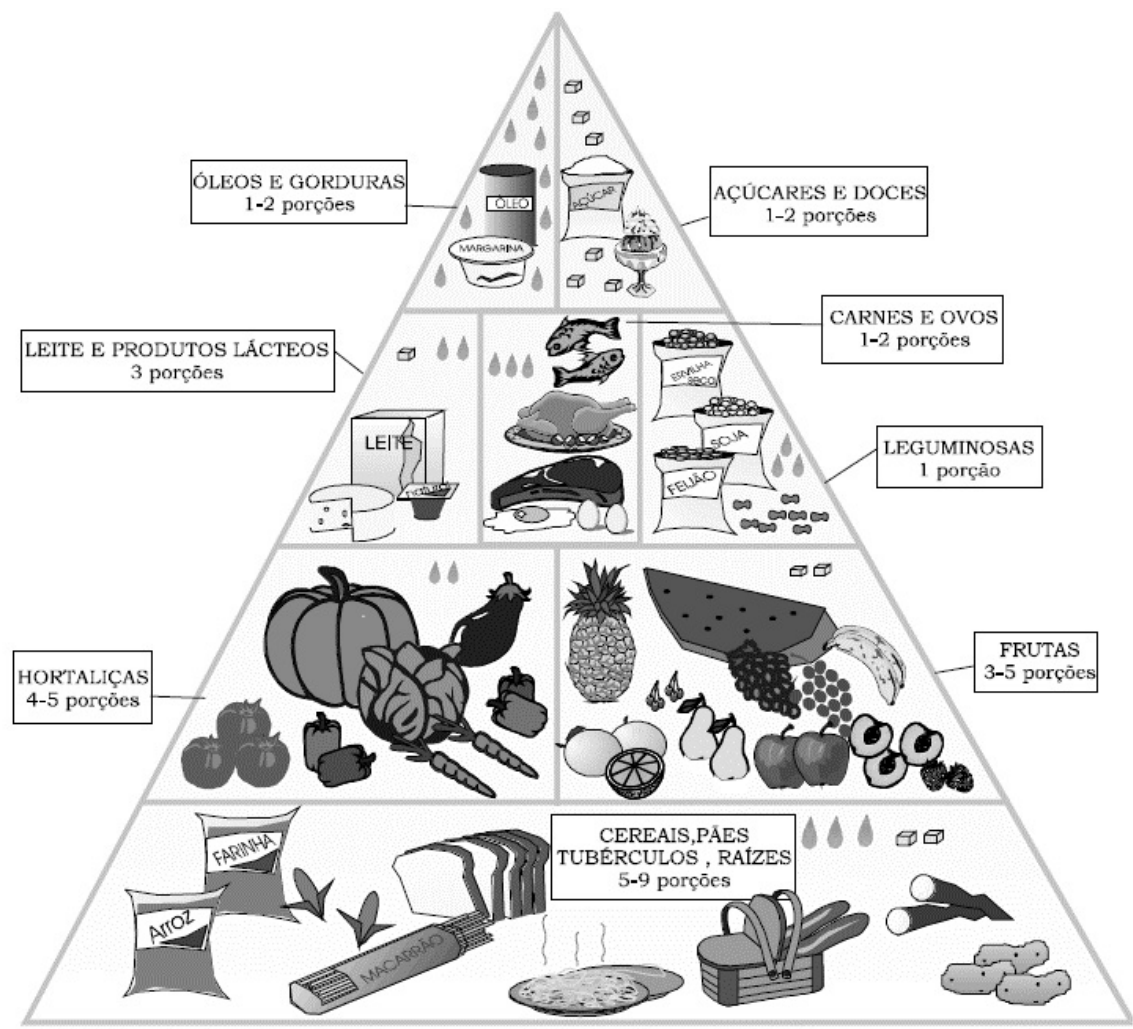

Fonte: Adaptada de Philippi et al. (1999).

Figura 5.1 Pirâmide alimentar 
7) Óleos e gorduras (margarina/manteiga, óleo): uma porção no mínimo, duas no máximo;

8) Açúcares e doces (doces, mel e açúcares): uma porção no mínimo, duas no máximo.

Em 2011, o Departamento da Agricultura dos Estados Unidos (USDA) lançou a sua nova Pirâmide Alimentar, denominada My Pyramid, apresentada na Figura 5.2 (USDA, 2011). A nova pirâmide tem o objetivo de motivar os indivíduos a selecionar alimentos saudáveis e de transmitir as informações científicas nutricionais mais atualizadas (BEEFPOINT, 2005).

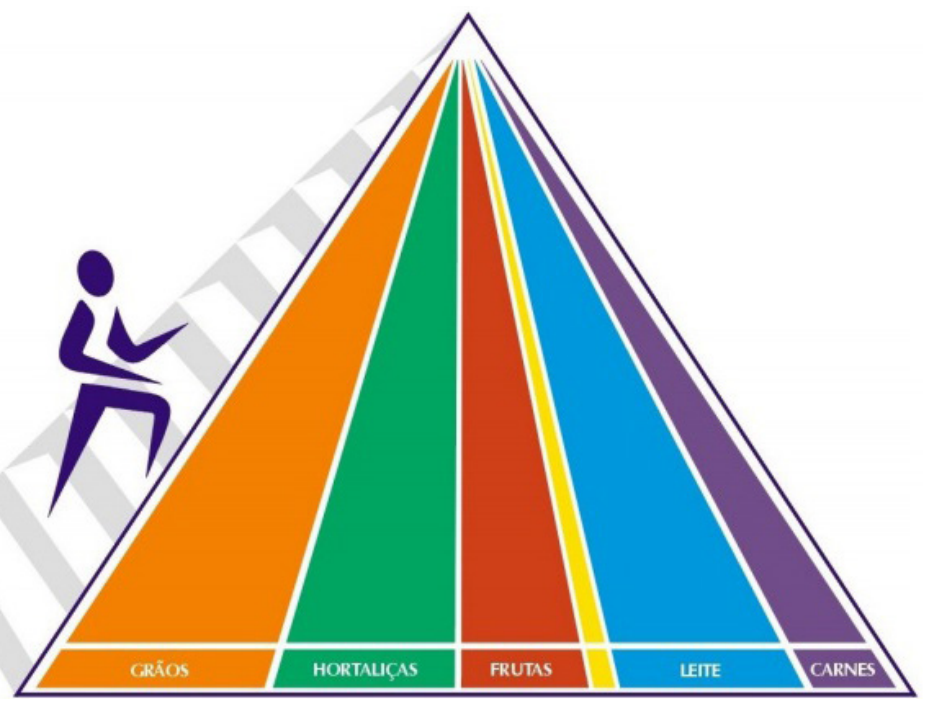

Fonte: Choose My Plate - USDA, 2011

\section{Figura 5.2 My Pyramid}

A principal mudança foi no número de grupos alimentares e os alimentos pertencentes a cada grupo, além da proporcionalidade entre estes grupos alimentares e da inclusão da atividade física como princípio de estilo de vida saudável, que é simbolizado por um indivíduo subindo uma escada, na lateral esquerda da pirâmide. Os grupos agora são: grãos, hortaliças, frutas, leite, carnes e óleos (BEEFPOINT, 2005).

Em junho de 2011, a USDA, lançou também um novo ícone de alimentos, o My Plate (Figura 5.3), que é dividido em quatros porções. Vegetais e grãos ocupam os quartos um pouco maiores, enquanto frutas e proteínas têm quartos um pouco menores. Os lácteos estão em um círculo separado, lembrando um copo de leite (USDA, 2011). 


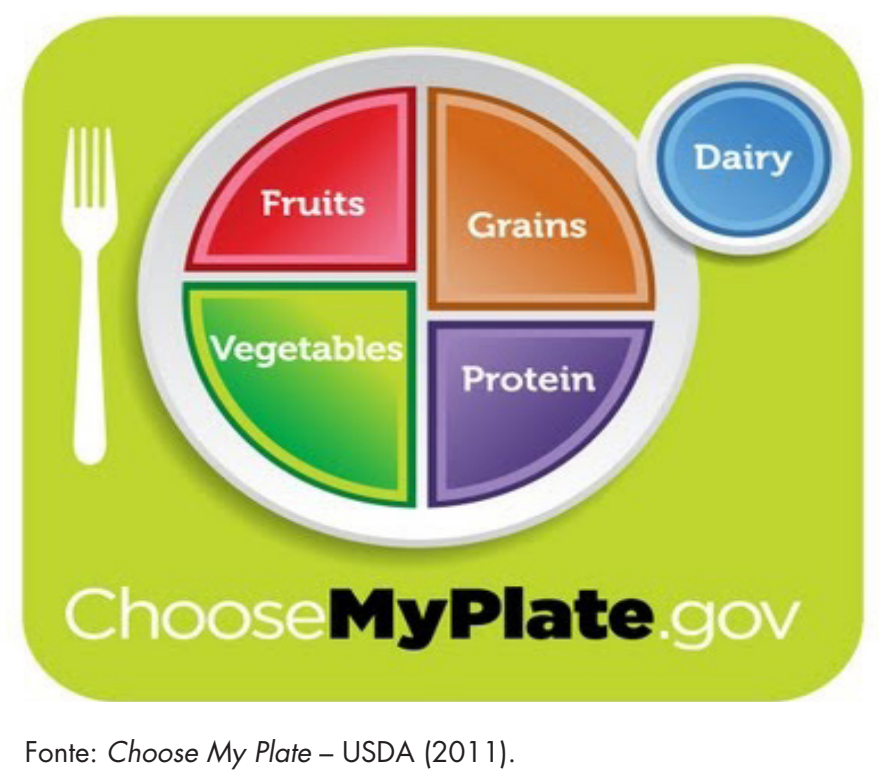

Figura 5.3 Choose my plate

O My Plate tem a intenção de servir como um lembrete para ajudar os consumidores a fazerem escolhas alimentares mais saudáveis, levando-os a pensar sobre a construção de um prato saudável no momento das refeições (USDA, 2011).

\subsection{Doenças relacionadas à alimentação inadequada}

Diabetes melito é uma doença crônica e de caráter hereditário, causada pela falta de produção ou produção insuficiente de insulina no organismo, que desencadeia níveis sanguíneos de glicose muito elevados, conhecidos como hiperglicemia. O indivíduo que, ao longo da vida, teve uma alimentação com excesso de açúcares e gorduras saturadas favorece o desenvolvimento do diabetes tipo 2. Esta doença não tem cura, então, depois de instalada, é necessário tratamento médico com medicamentos, alimentação específica e atividade física (OLIVEIRA; ROMAN, 2013).

A obesidade é o acúmulo excessivo de gordura corporal, causado pelo desequilíbrio entre gasto energético e consumo de alimentos, que acarreta diversos prejuízos à saúde do indivíduo, como dificuldade respiratória, problemas dermatológicos, problemas psicológicos, resistência à insulina, além de favorecer doenças cardiovasculares, entre outras. O tratamento da obesidade engloba o controle da ingestão alimentar e também mudanças de hábitos, incluindo prática de atividade física (OLIVEIRA; ROMAN, 2013).

As dislipidemias baseiam-se na alteração dos níveis de lipídeos no sangue. Há vários tipos, sendo os mais comuns a hipercolesterolemia e a hipertrigliceridemia. 
A hipercolesterolemia consiste no excesso de colesterol e/ou lipoproteínas de baixa densidade (low density lipoprotein - LDL) no sangue. Ocorre por hereditariedade ou ingestão excessiva de gordura saturada e colesterol alimentar. O colesterol excessivo nos vasos sanguíneos leva a aterosclerose. Para diminuição desta doença, é necessária ingestão de fibras alimentares, exercício físico e restrição do consumo de colesterol, gorduras saturadas e trans (OLIVEIRA; ROMAN, 2013).

Já hipertrigliceridemia deve-se ao aumento de triglicerídeos no sangue, normalmente causado pelo aumento de lipoproteínas de baixa densidade ou quilomícrons. Tal doença ajuda na instalação ou agravamento da aterosclerose. Para seu controle, é necessário reduzir a ingestão de gorduras saturadas e álcool, além de limitar a ingestão de gorduras saturadas e alimentos ricos em ômega 3 (OLIVEIRA; ROMAN, 2013).

\subsection{Perfil alimentar moderno}

As mudanças no estilo de vida da população se refletem diretamente nos hábitos alimentares, surgindo, assim, a busca por novos produtos e novas formas de consumo. Dentre as principais transformações está o aumento no consumo fora do domicílio, com destaque para as redes fast-food e restaurantes por quilo, que apresentam a praticidade, rapidez, conveniência e adequação aos desejos dos consumidores. A grande demanda por conveniência se dá principalmente pelo aumento da participação da mulher no mercado de trabalho e de domicílios habitados por menor número de pessoas (NEVES; CHADDAD; LAZZARINI, 2003).

Os jovens universitários normalmente apresentam hábitos menos saudáveis, fazendo suas refeições em horários não padronizados, muitas vezes fora de casa e na sua grande maioria com alimentos que podem causar males à saúde, fazendo-se necessário o aumento do consumo de alimentos mais saudáveis e mais próximos de uma refeição tradicional (BORGES, 2013).

Portanto, o principal desafio na formulação e na implementação de estratégias para uma alimentação saudável está em torná-la viável em um contexto no qual os papéis, os valores e o sentido de tempo estão em constante mudança (BRASIL, 2006).

\subsection{Ficha técnica de preparo (FTP)}

Os setores de alimentação vêm se expandindo nos últimos tempos, acompanhando as necessidades da população. Frente a um mercado muito competitivo e globalizado, a padronização vem sendo vista como peça fundamental para o gerenciamento e controle de qualidade dos alimentos a fim de padronizar os processos e promover alta qualidade na produção de refeições. A padronização do 
processo de produção de refeições beneficia desde o nutricionista até os funcionários, facilitando a execução de tarefas e aumentando a segurança no local de trabalho (AKUTSU et al., 2005).

A Ficha Técnica de Preparo (FTP) é utilizada como forma de apoio, indicando os custos, a ordenação do preparo, como tempo de preparo, procedimentos e complexidade, e o cálculo do valor nutricional das preparações (VASCONCELLOS et al., 2002² apud AKUTSU et al., 2005, p. 278). Com ela é possível obter a composição centesimal em macro e micronutrientes da preparação, contribuindo para a elaboração de um cardápio equilibrado e balanceado nutricionalmente. Sua implementação beneficia todas as categorias envolvidas no processo de produção.

O Quadro 5.1 apresenta um exemplo de Ficha Técnica de Preparo de alimentos.

Quadro 5.1 Ficha técnica - Torta de batata ralada

\begin{tabular}{l|c|c|c|c}
\hline \multicolumn{1}{c}{ Ingredientes } & \multicolumn{1}{c}{$\mathrm{PB}^{*}$} & \multicolumn{1}{c}{$\mathrm{PL}^{*}$} & $\mathrm{FC}^{*}$ & Medida caseira \\
\hline Batata & $4262 \mathrm{~g}$ & $3552 \mathrm{~g}$ & 1,2 & 11 batatas grandes \\
\hline Creme de leite & $400 \mathrm{~g}$ & $400 \mathrm{~g}$ & 1 & $\begin{array}{c}2 \text { unidades comer- } \\
\text { ciais }\end{array}$ \\
\hline Queijo prato & $504 \mathrm{~g}$ & $504 \mathrm{~g}$ & 1 & 18 fatias \\
\hline Cebola & $542 \mathrm{~g}$ & $480 \mathrm{~g}$ & 1,13 & 3 cebolas médias \\
\hline Leite integral & $3000 \mathrm{~g}$ & $3000 \mathrm{~g}$ & 1 & 3 litros \\
\hline $\begin{array}{l}\text { Margarina com sal } \\
\text { Farinha de trigo } \\
\text { comum }\end{array}$ & $94 \mathrm{~g}$ & $94 \mathrm{~g}$ & 1 & 3 colheres de sopa \\
\hline Total & $300 \mathrm{~g}$ & $300 \mathrm{~g}$ & 1 & 2 xícaras cheias \\
\hline
\end{tabular}

\begin{tabular}{|l|l}
\hline Peso líquido final g: 5384 & $\mathrm{~PB}=$ peso bruto \\
\hline Rendimento: & $\mathrm{PL}=$ peso líquido \\
\hline Peso da porção (g): 200 & $\mathrm{FC}=$ fator de correção \\
\cline { 1 - 2 } Medida caseira: 1 pedaço médio &
\end{tabular}

2 VASCONCELLOS F.; CAVALCANTI E.; BARBOSA L. Menu: como montar um cardápio eficiente. São Paulo: Roca, 2002. 
Per capita:

\begin{tabular}{l|c|c|c|c}
\multicolumn{1}{c}{ Ingredientes } & PB* & \multicolumn{1}{c}{ PL* $^{*}$} & FC* $^{*}$ & Medida caseira \\
\hline Batata & $158 \mathrm{~g}$ & $132 \mathrm{~g}$ & 1,2 & 1 unidade grande \\
\hline Creme de leite & $15 \mathrm{~g}$ & $15 \mathrm{~g}$ & 1 & $\begin{array}{c}1 \text { colher de sopa } \\
\text { cheia }\end{array}$ \\
\hline Queijo prato & $19 \mathrm{~g}$ & $19 \mathrm{~g}$ & 1 & $1 / 2$ fatia \\
\hline Cebola & $20 \mathrm{~g}$ & $18 \mathrm{~g}$ & 1,13 & 1 colher de sopa \\
\hline Leite integral & $111 \mathrm{~g}$ & $111 \mathrm{~g}$ & 1 & $\begin{array}{c}2 ; 3 \text { de copo } \\
\text { americano }\end{array}$ \\
\hline Margarina com sal & $3 \mathrm{~g}$ & $3 \mathrm{~g}$ & 1 & 1 colher de chá rasa \\
\hline $\begin{array}{l}\text { Farinha de trigo } \\
\text { comum }\end{array}$ & $11 \mathrm{~g}$ & $11 \mathrm{~g}$ & 1 & $\begin{array}{c}1 \text { colher de } \\
\text { sopa rasa }\end{array}$ \\
\hline Total & $338 \mathrm{~g}$ & $309 \mathrm{~g}$ & & \\
\hline
\end{tabular}

\section{A porção contém:}

\begin{tabular}{lrllr} 
Calorias & 347,38 & D (mcg) & 0,04 \\
\hline Carboidratos & 40,11 & Niacina $(\mathrm{mg})$ & 2,18 \\
\hline Gordura total & 15,65 & Ac. Fólico $(\mathrm{mcg})$ & 25,76 \\
\hline Gordura poliinsaturada & 0,256 & B5 $(\mathrm{mg})$ & 0,61 \\
\hline Gordura monoiinsaturada & 1,54 & $\mathrm{E}(\mathrm{mg})$ & 1,23 \\
\hline Gordura saturada & 3,36 & lodo $(\mathrm{mcg})$ & 0,36 \\
\hline Proteínas & 11,52 & Na $(\mathrm{mg})$ & 207,61 \\
\hline Fibra total & 2,81 & Ca $(\mathrm{mg})$ & 165,26 \\
\hline Fibras solúveis & 0,62 & Magnésio $(\mathrm{mg})$ & 37,3 \\
\hline Fibras insolúveis & 1,79 & Zinco $(\mathrm{mg})$ & 1,32 \\
\hline Colesterol & 16,7 & Manganês $(\mathrm{mg})$ & 0,44 \\
\hline A (RE) & 62,03 & K (mg) & 796,38 \\
\hline C (mg) & 27,13 & P (mg) & 179,19 \\
\hline B1 (mg) & 0,17 & Fe $(\mathrm{mg})$ & 1,35 \\
\hline B2 (mg) & 0,13 & Cobre $(\mathrm{mg})$ & 0,03 \\
\hline B6 (mg) & 0,4 & Selênio $(\mathrm{mg})$ & 2,15 \\
\hline B12 (mcg) & 0,29 & &
\end{tabular}

\section{Modo de fazer:}

Corte a batata em rodelas finas e deixe cozinhar até ficar em consistência macia.

Escorra e reserve.

Molho branco: Refogue a cebola juntamente com a manteiga, junte a farinha e mexa vigorosamente para não formar grumos, acrescente o leite aos poucos até ficar homogêneo.

Misture o creme de leite.

Montagem: $1^{\circ}$ camada: batata, $2^{\circ}$ camada: molho branco, $3^{\circ}$ camada: queijo, $4^{\circ}$ camada: batata, $5^{\circ}$ camada: molho branco. $6^{\circ}$ camada: queijo. Sirva. 


\subsection{Informação nutricional nos cardápios}

A informação nutricional é a representação de que um alimento possui determinadas propriedades nutricionais quanto ao valor energético, conteúdo de proteínas, gorduras, carboidratos, fibras alimentares, vitaminas e ou minerais (BRASIL, 2012).

Com o aumento no interesse da população em conhecer a função e importância da alimentação na saúde, surge a necessidade de se obter informação a respeito dos nutrientes presentes nesses alimentos. O modo com que o alimento é manipulado, processado e conservado pode torná-lo inadequado para consumo. As Unidades de Alimentação e Nutrição (UAN) devem atender às recomendações nutricionais diárias de energia, oferecendo um cardápio que contenha os grupos de alimentos diversificados e isento de riscos de enfermidades, com atenção aos custos e à aceitação do usuário. Um restaurante universitário (RU) deve estar dentro das especificações acima, apresentando refeições adequadas e considerando os aspectos higiênico-sanitários (OLIVEIRA; GUAGLIANONI; DEMONTE, 2005).

O Quadro 5.2 apresenta um modelo do cardápio do Restaurante Universitário da Universidade Estadual de Campinas (UNICAMP), contendo as informações nutricionais de cada alimento que o compõe.

Quadro 5.2 Cardápio Restaurante Universitário UNICAMP, adaptado pelo autor

\begin{tabular}{|c|c|c|c|c|c|}
\hline \multicolumn{6}{|c|}{ Cardápio: almoço - restaurante universitário Unicamp } \\
\hline & Medida RU & $\begin{array}{c}\text { Carboidrato } \\
\text { (g) }\end{array}$ & $\begin{array}{l}\text { Proteína } \\
\text { (g) }\end{array}$ & $\begin{array}{l}\text { Lipídeo } \\
\text { (g) }\end{array}$ & $\begin{array}{l}\text { Calorias } \\
\text { (Kcal) }\end{array}$ \\
\hline Arroz & 1 Concha $(110 \mathrm{~g})$ & 29 & 3 & 4 & 168 \\
\hline Feijão & 1 Concha $(120 \mathrm{~g})$ & 10 & 4 & 3 & 82 \\
\hline $\begin{array}{c}\text { Peixe ao } \\
\text { molho } \\
\text { branco }\end{array}$ & 1 Porção (120 g) & 4,5 & 28,6 & 4,4 & 171,5 \\
\hline $\begin{array}{c}\text { Pepino, } \\
\text { tomate, } \\
\text { pimentão }\end{array}$ & 1 pegador $(90 \mathrm{~g})$ & 3,15 & 0,67 & 0 & 17,8 \\
\hline Maçã & 1 Unidade & 13,7 & 0,3 & 0 & 55,8 \\
\hline Suco de manga & 1 Copo (200 ml) & 16 & 0 & 0 & 64 \\
\hline Pão francês & 1 Unidade $(20 \mathrm{~g})$ & 12 & 1,6 & 0,6 & 59 \\
\hline $\begin{array}{l}\text { Café com } \\
\text { açúcar }\end{array}$ & 1 copo (45 ml) & 2,8 & 0,3 & 0,27 & 15 \\
\hline TOTAL & & 91,5 & 38,47 & 12,27 & 633,1 \\
\hline
\end{tabular}


Informações Adicionais

\begin{tabular}{llcccc}
\hline Porção & $\begin{array}{c}\text { Carboidrato } \\
(\mathbf{g})\end{array}$ & $\begin{array}{c}\text { Proteína } \\
(\mathbf{g})\end{array}$ & $\begin{array}{c}\text { Lipideo } \\
(\mathbf{g})\end{array}$ & $\begin{array}{c}\text { Calorias } \\
\text { (Kcal) }\end{array}$ \\
\hline Arroz Integral & 1 Concha $(90 \mathrm{~g})$ & 22,1 & 2,3 & 4 & 134 \\
\hline Cardápio contém glúten no pão e no peixe ao molho branco, e contém lactose no \\
peixe ao molho branco
\end{tabular}

Fonte: Restaurante Universitário UNICAMP, 2013.

\subsection{Restaurante universitario da UTFPR - campus Londrina}

A Universidade Tecnológica Federal do Paraná (UTFPR) - campus Londrina foi implantada em 2007, situada provisoriamente no prédio da Fundação de Ensino Técnico de Londrina (FUNTEL). Em 2009, suas atividades foram transferidas para as instalações definitivas, na Gleba Lindóia, continuação da Estrada dos Pioneiros, região Leste da cidade. O campus Londrina conta com mais de 1.000 alunos, 118 professores (efetivos e contratados) e 52 servidores técnico-administrativos (UTFPR, 2014).

O restaurante do campus foi inaugurado em 19 de outubro de 2012. Desde então, fornece almoço de segunda a sábado e jantar de segunda a sexta-feira. A área construída é de aproximadamente 738,55 m², com capacidade para atender cerca de 300 pessoas simultaneamente. A unidade dispõe de uma cozinha industrial, com capacidade para o preparo de até 800 refeições/dia. No ano de 2013 a unidade da UTFPR contou com o contrato de duas empresas terceirizadas, no primeiro semestre com a empresa Edikasa e, posteriormente, com a empresa Costela Grill, unidade provisória que permaneceu até o fim do ano. A empresa contratada na ocasião da realização deste trabalho é a La Francine's, com contrato até o final de 2014.

A empresa La Francine's é de Londrina e foi fundada em 1984. No início, era um quiosque de marmitas no calçadão de Londrina. Em 1989, inaugurou o primeiro restaurante de comida por quilo em Londrina, situado à Avenida Minas Gerais. Mudou-se para a Rua Pio XII, e já recebia o nome de La Francine’s. Em 1996, foi inaugurado o Buffet La Francine's, localizado na Avenida Rio Branco, sede atual da empresa (ROCHA, 2014).

A partir de 2000, a concorrência em relação a restaurantes por quilo passou a ser muito alta na região de Londrina, então a empresa encontrou outra oportunidade de negócio, começou a terceirizar seus restaurantes e participar de licitações (ROCHA, 2014).

Hoje em dia a empresa possui apenas o Buffet e seus serviços de terceirização, pois o restaurante situado na Rua Pio XII foi fechado em fevereiro de 2014. A 
empresa conta com 60 funcionários e, além destes, chega a terceirizar cerca de 50 funcionários, de acordo com suas necessidades. O restaurante La Francine’s já prestou serviços de terceirização em diversas empresas da região, como Embrapa Soja, Prefeitura de Londrina e locais onde estão até hoje, como Hospital Universitário, Maternidade de Londrina, APS e UPAS de Londrina e agora, também, na Universidade Tecnológica Federal do Paraná - campus Londrina (ROCHA, 2014).

No campus Londrina da UTFPR, o restaurante iniciou suas atividades em 17 de janeiro de 2014, e tem contrato até o fim do ano vigente. Na Universidade, a empresa conta com 12 funcionários, que trabalham em dois turnos, e uma nutricionista (ROCHA, 2014).

\section{MATERIAIS E MÉTODOS}

Esta pesquisa foi realizada no período de janeiro a maio de 2014, no laboratório de análise de alimentos da Universidade Tecnológica Federal do Paraná (UTFPR) - campus Londrina. Trata-se de uma pesquisa experimental e descritiva, com o intuito de analisar a composição proximal dos alimentos mais frequentemente servidos pelo Restaurante Universitário (RU) da UTFPR - campus Londrina, com foco na verificação do valor nutricional desaes alimentos.

Foram analisadas amostras dos alimentos, baseadas nas preparações servidas com maior frequência, servidos no RU da Universidade Tecnológica Federal do Paraná - campus Londrina.

\subsection{Levantamento de dados}

A princípio, foi realizado um levantamento das preparações mais frequentemente servidas pelo RU através dos cardápios acumulados dos últimos três meses, fornecidos pela equipe do restaurante. Antes do levantamento de dados, foi definido que a pesquisa seria realizada com sete alimentos, dentre os quais deveriam estar presentes arroz e feijão (base das refeições servidas diariamente), um acompanhamento, uma guarnição e uma variação de cada tipo de carne: bovina, suína e de frango.

As preparações mais frequentemente servidas selecionadas foram: arroz, feijão, como acompanhamento o macarrão alho e óleo, como guarnição a batata sauté e as variações de carnes, sendo que as mais servidas em cada grupo foram sobrecoxa de frango assado, bife bovino frito e bisteca suína frita.

\subsection{Amostras}

Para cada um dos sete alimentos selecionados, foram coletadas três amostras em sacos plásticos com lacre, em dias distintos, no Restaurante Universitário, sem 
o conhecimento prévio dos funcionários do restaurante para que não houvesse interferência na forma do preparo e manipulação destes alimentos.

As amostras foram homogeneizadas utilizando um liquidificador, em seguida foram colocadas de volta no saco plástico com lacre e encaminhadas para o congelador.

Cada uma das três amostras coletadas de um mesmo alimento foi analisada em triplicata e, em seguida, foi realizado o cálculo da média das amostras com relação a porções de $100 \mathrm{~g}$.

\subsection{Análises físico-químicas}

Foram realizadas análises físico-químicas para quantificar os teores de proteínas, lipídeos, umidade e cinzas, e posterior determinação do teor de carboidratos por diferença e cálculo de calorias de cada amostra.

\subsubsection{Umidade}

A quantidade de água contida no alimento foi determinada utilizando o método de perda de umidade por dessecação, com secagem direta em estufa á 105 ${ }^{\circ} \mathrm{C}$, para obtenção do resíduo seco (IAL, 2008).

As análises de umidade foram realizadas imediatamente após as coletas e homogeneização de cada amostra.

Foram pesadas aproximadamente $5 \mathrm{~g}$ de cada amostra em cápsulas de porcelana, estando estas previamente taradas. Estas cápsulas foram colocadas na estufa a $105^{\circ} \mathrm{C}$ e aquecidas por três horas inicialmente, em seguida foram resfriadas em dessecador até atingir a temperatura ambiente, operação que foi repetida, deixando a amostra de uma em uma hora na estufa, até o resultado final com peso constante. Então a cápsula foi novamente pesada, e a operação de aquecimento e resfriamento foi repetida, até que essas cápsulas atingissem peso constante (IAL, 2008).

Para calcular a quantidade de água contida no alimento, a variação de peso da amostra verificada após o processo foi convertida em \%, em função do peso inicial desta, de acordo com a Equação 1.

$$
\frac{100 \times \mathrm{N}}{\mathrm{P}}=\%(\mathrm{~m} / \mathrm{m}) \text { umidade ou substâncias voláteis a } 105^{\circ} \mathrm{C}
$$

Onde:

$\mathrm{N}=$ perda de peso em $\mathrm{g}$

$\mathrm{P}=\mathrm{n}^{\circ}$ de gramas de amostra

Equação 1 - Expressão matemática para o cálculo do teor de umidade. 


\subsubsection{Cinzas}

O método utilizado para determinar as cinzas totais nos alimentos foi o de resíduo por incineração, que é o resíduo obtido por aquecimento de um produto em temperatura de aproximadamente $550^{\circ} \mathrm{C}$, utilizando mufla. Esse método fundamenta-se em oxidar totalmente a matéria orgânica, e obter um resíduo mineral fixo, que foi convertido em \% (IAL, 2008).

Os cadinhos de porcelana utilizados na análise foram previamente calcinados a $550{ }^{\circ} \mathrm{C}$ por uma hora, resfriados em dessecador até temperatura ambiente e pesados. Foram, então, pesadas aproximadamente $5 \mathrm{~g}$ da amostra nestes cadinhos, foi realizada carbonização em chama direta, e em seguida os cadinhos foram colocados em mufla a $550^{\circ} \mathrm{C}$ por $6-8$ horas. As cinzas ficaram brancas ou ligeiramente acinzentadas. As amostras foram resfriadas em dessecador até a temperatura ambiente e pesadas. Esta operação foi repetida até peso constante, e, então, foi pesado o cadinho com o resíduo fixo final (IAL, 2008). Para o teor de cinzas, foi utilizada a Equação 2.

$$
\frac{100 \times \mathrm{N}}{\mathrm{P}}=\% \text { Cinzas }
$$

Onde:

$\mathrm{N}=\mathrm{n}^{\circ}$ de gramas de cinzas

$\mathrm{P}=\mathrm{n}^{\circ}$ de gramas de amostra

Equação 2 - Expressão matemática para o cálculo do teor de cinzas.

\subsubsection{Lipídeos}

O método utilizado foi o de extração direta em Soxhlet, que se fundamenta na solubilidade dos lipídios em solvente orgânico apropriado. O reagente utilizado para esta análise foi o éter de petróleo (AOAC, 1995).

As amostras de arroz e feijão foram analisadas no extrator tipo Soxhlet (Figura 5.4), onde foram pesadas $5 \mathrm{~g}$ das amostras já homogeneizadas e trituradas, em papéis de filtro, e estes foram lacrados com grampos. Estes papéis foram previamente pesados e secos por uma hora em estufa, e transferidos para o aparelho extrator tipo Soxhlet. O extrator foi acoplado ao balão de fundo chato previamente tarado a $105^{\circ} \mathrm{C}$. Adicionou-se aproximadamente $100 \mathrm{ml}$ de éter de petróleo em cada um dos 6 extratores, e adaptou-se um condensador de bolas ao extrator de Soxhlet. O aquecimento em chapa elétrica foi ligado e mantido, a extração continuou por aproximadamente seis horas, havendo a necessidade de repor o éter de petróleo várias vezes nos extratores. Retiraram-se os papéis de 
filtro e realizou-se a destilação do éter de petróleo ainda presente. Os balões com o resíduo extraído foram transferidos para a estufa a $105^{\circ} \mathrm{C}$, por cerca de uma hora, em seguida foram resfriados em dessecador até a temperatura ambiente. Pesaram-se os balões, e repetiram-se as operações de aquecimento por trinta minutos na estufa e resfriamento até peso constante (AOAC, 1995).
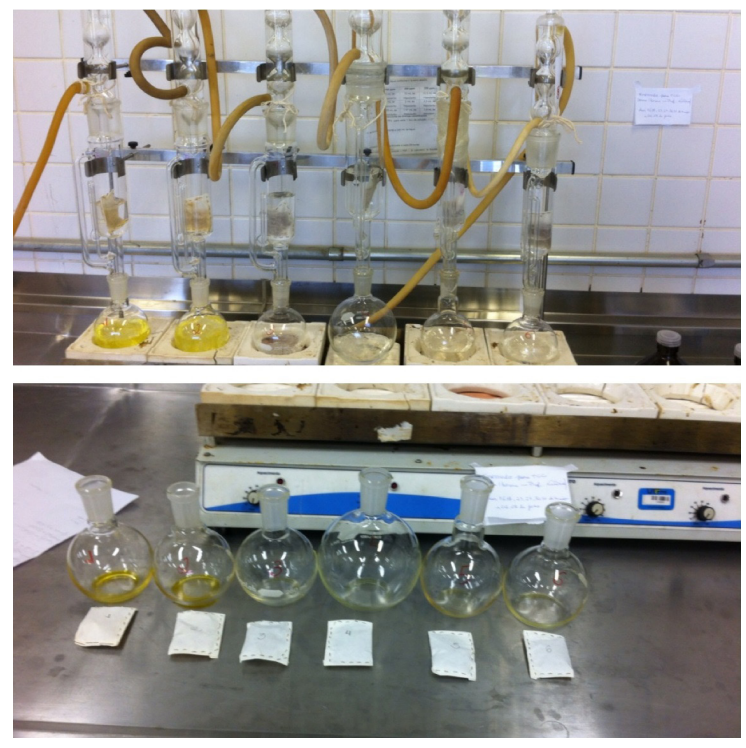

Figura 5.4 Extrator Soxhlet (UTFPR - campus Londrina)

As demais amostras foram analisadas no extrator Soxtec ${ }^{\mathrm{TM}}$ (FOSS, 2014) do Programa de Mestrado em Tecnologia de Alimentos da UTFPR - campus Londrina. Este equipamento realiza a extração de lipídeo das amostras pelo mesmo princípio da determinação de Soxhlet, porém, é automatizado, utiliza cerca de $60 \mathrm{ml}$ de solvente por amostra durante toda a análise, utilizam-se recipientes de alumínio ao invés de balões de vidro e a extração está completa em aproximadamente setenta minutos. As extrações no Soxtec (Figura 5.5) foram realizadas a $110{ }^{\circ} \mathrm{C}$. O cálculo do teor de lipídeos na amostra foi realizado utilizando a Equação 3.

$$
\frac{100 \times \mathrm{N}}{\mathrm{P}}=\% \text { de lipídios na amostra }(\mathrm{m} / \mathrm{m})
$$

Onde

$\mathrm{N}=\mathrm{n}^{\circ}$ de gramas de lipídio

$\mathrm{P}=\mathrm{n}^{\circ}$ de gramas da amostra

Equação 3 - Expressão matemática para o cálculo do teor de lipídios. 

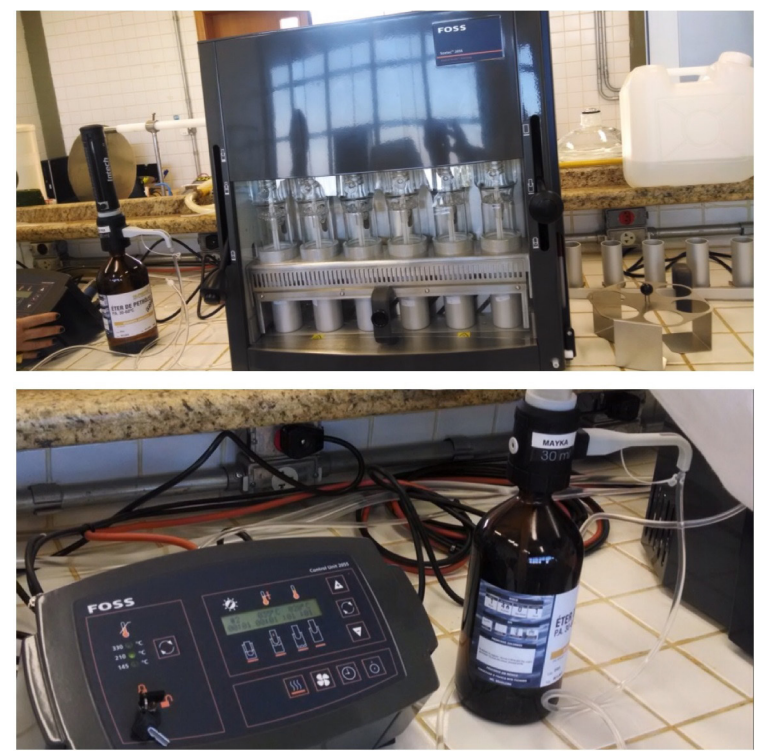

Figura 5.5 Equipamento Soxtec - FOSS (UTFPR - campus Londrina)

\subsubsection{Proteína}

A determinação de proteínas brutas foi realizada pelo método de Micro Kjeldahl, que se baseia na determinação do nitrogênio total, dividido em três etapas (AOAC, 1995):

- DIGESTÃO - a matéria orgânica existente na amostra será decomposta com ácido sulfúrico e um catalisador, transformando o nitrogênio em sal amoniacal.

- DESTILAÇÃO - a amônia será liberada do sal amoniacal pela reação com hidróxido e recebida numa solução ácida de volume e concentração conhecidos.

- TITULAÇÃO - a quantidade de nitrogênio presente na amostra é determinada titulando-se o excesso do ácido utilizado na destilação com hidróxido.

Dentre os reagentes utilizados, foi necessário o preparo de uma mistura catalítica composta por sulfato de cobre $\left(\mathrm{CuSo}_{4}\right)$ e sulfato de potássio $\left(\mathrm{K}_{2} \mathrm{SO}_{4}\right)$ na proporção 0,2:1,0 g (AOAC, 1995).

A análise se inicia no procedimento de digestão, onde foram pesadas $0,2 \mathrm{~g}$ da amostra em papel de seda previamente tarado, transferida, junto com o papel de seda para um tubo de Kjeldahl, ou tubo de digestão, onde foram adicionados 5 
ml de ácido sulfúrico e cerca de $0,2 \mathrm{~g}$ da mistura catalítica. Os tubos foram então colocados no bloco digestor de aquecimento, na capela de exaustão, iniciando-se com $100{ }^{\circ} \mathrm{C}$ e aumentando-se gradativamente a temperatura até $400{ }^{\circ} \mathrm{C}$, para não acarretar perdas na amostra. A digestão é considerada completa quando a solução estiver límpida e tornar-se azul-esverdeada a quente, e livre de material não digerido (pontos pretos), e então o bloco destilador foi desligado (AOAC, 1995).

Seguiu-se, então, para o processo de destilação. O aparelho de destilação de Kjeldahl deve ser ligado trinta minutos antes do início da análise, iniciando o aquecimento e a circulação de água para que sua caldeira se preencha até o nível adequado do equipamento.

Primeiramente, com o tubo frio, foram adicionados $10 \mathrm{ml}$ de água destilada ao tudo digestor para diluição, e acoplado o balão com as proteínas digeridas ao aparelho digestor. Em seguida, foi adicionado hidróxido de sódio $(\mathrm{NaOH}) 50 \%$ no funil dosador de soda que, neste momento, deve estar com a torneira fechada. O aquecimento do aparelho foi desligado, e a torneira dosadora de soda foi aberta lentamente, adicionando soda aos poucos na amostra, até que esta fosse neutralizada, obtendo cor marrom-esverdeado escuro (AOAC, 1995).

Encaixou-se um erlenmeyer de $125 \mathrm{ml}$ na saída do condensador, contendo $10 \mathrm{ml}$ de acido bórico $\left(\mathrm{H}_{3} \mathrm{BO}_{4}\right) 2 \%$ com 3 gotas do indicador misto (vermelho de metila e verde de bromocresol) $0,1 \%$. Ligou-se novamente o aquecimento do aparelho e aguardou-se a destilação ocorrer, até a coleta de $50 \mathrm{ml}$ do destilado, que terá coloração rósea. Terminada a destilação, o aquecimento do destilador foi desligado, e o erlenmeyer e o tubo de Kjeldahl foram retirados (AOAC, 1995).

$\mathrm{Na}$ última etapa da análise, é realizada a titulação do destilado. Preparou-se uma bureta com $50 \mathrm{ml}$ de ácido sulfúrico $\left(\mathrm{H}_{2} \mathrm{SO}_{4}\right)$ 0,02 N padronizado, titulou-se o destilado diretamente no erlenmeyer em que foi coletado até neutralização (coloração verde claro translúcido) e foi anotado o volume $(\mathrm{ml})$ necessário para a neutralização (AOAC, 1995). Para realizar o cálculo do teor de proteína bruta nas amostras, foi utilizada a EQUAÇÃO 4.

\section{$(\mathrm{V}-\mathrm{B}) \times \mathrm{N} \times \mathrm{F} \times 0,014 \times \mathrm{fc} \times 100=\%$ de proteínas na amostra $\mathrm{P}$}

Onde:

$\mathrm{V}=$ volume de ácido sulfúrico gasto na titulação

$\mathrm{B}=$ branco

$\mathrm{N}=$ normalidade do ácido sulfúrico $\left(\mathrm{H}_{2} \mathrm{SO}_{4}\right): 0,02 \mathrm{~N}$

$\mathrm{F}$ = fator de correção do ácido: 0,9985

$\mathrm{fc}=$ fator de conversão (o conteúdo de nitrogênio das diferentes proteínas é de aproximadamente $16 \%$, então utiliza-se o fator empírico 6,25 para transformar o número de gramas de nitrogênio encontrado em número de gramas de proteína) 
$\mathrm{P}=$ peso da amostra

Equação 4 - Expressão matemática para o cálculo do teor de proteína.

\subsubsection{Carboidratos}

O teor de carboidratos totais foi calculado por diferença, isto é, as porcentagens de água, proteína, lipídeos totais e cinzas foram somadas e subtraídas de cem. A porcentagem restante é a quantidade de carboidrato.

\subsection{Valor energético}

Para o cálculo do valor energético, foram utilizados os seguintes fatores de conversão (BRASIL, 2003):

Carboidratos - $4 \mathrm{kcal}$ para cada grama de carboidrato - $17 \mathrm{~kJ} / \mathrm{g}$;

Proteínas - $4 \mathrm{kcal}$ para cada grama de proteína $-17 \mathrm{~kJ} / \mathrm{g}$;

Gorduras 9 - kcal para cada grama de lipídeo - 37 kJ/g.

\subsection{Análise estatística}

As médias e o desvio padrão entre as triplicatas de cada amostra foram realizadas com o auxílio do programa Microsoft Excel 2010. Para comparar os resultados de análise das três amostras de cada alimento coletadas em dias diferentes, foi realizada Análise de Variância (ANOVA) e comparação entre médias pelo teste de Tukey, com o auxílio do software Statistica 8.0.

\subsection{Elaboração do informativo}

Tendo definida a composição e os valores energéticos em porções de $100 \mathrm{~g}$ dos alimentos selecionados por serem servidos com maior frequência pelo RU da UTFPR - campus Londrina, foi elaborado um informativo na forma de folhetos adesivos contendo os resultados obtidos e recomendações para a elaboração de um prato balanceado. Estes informativos foram colados nas mesas do RU, com o intuito chamar a atenção dos alunos e servidores para sua leitura, e esclarecer quanto à composição dos alimentos servidos.

\section{RESULTADOS E DISCUSSÃO}

Os resultados da composição proximal dos alimentos mais frequentemente servidos no Restaurante Universitário da UTFPR - Londrina estão na Tabela 5.2. 


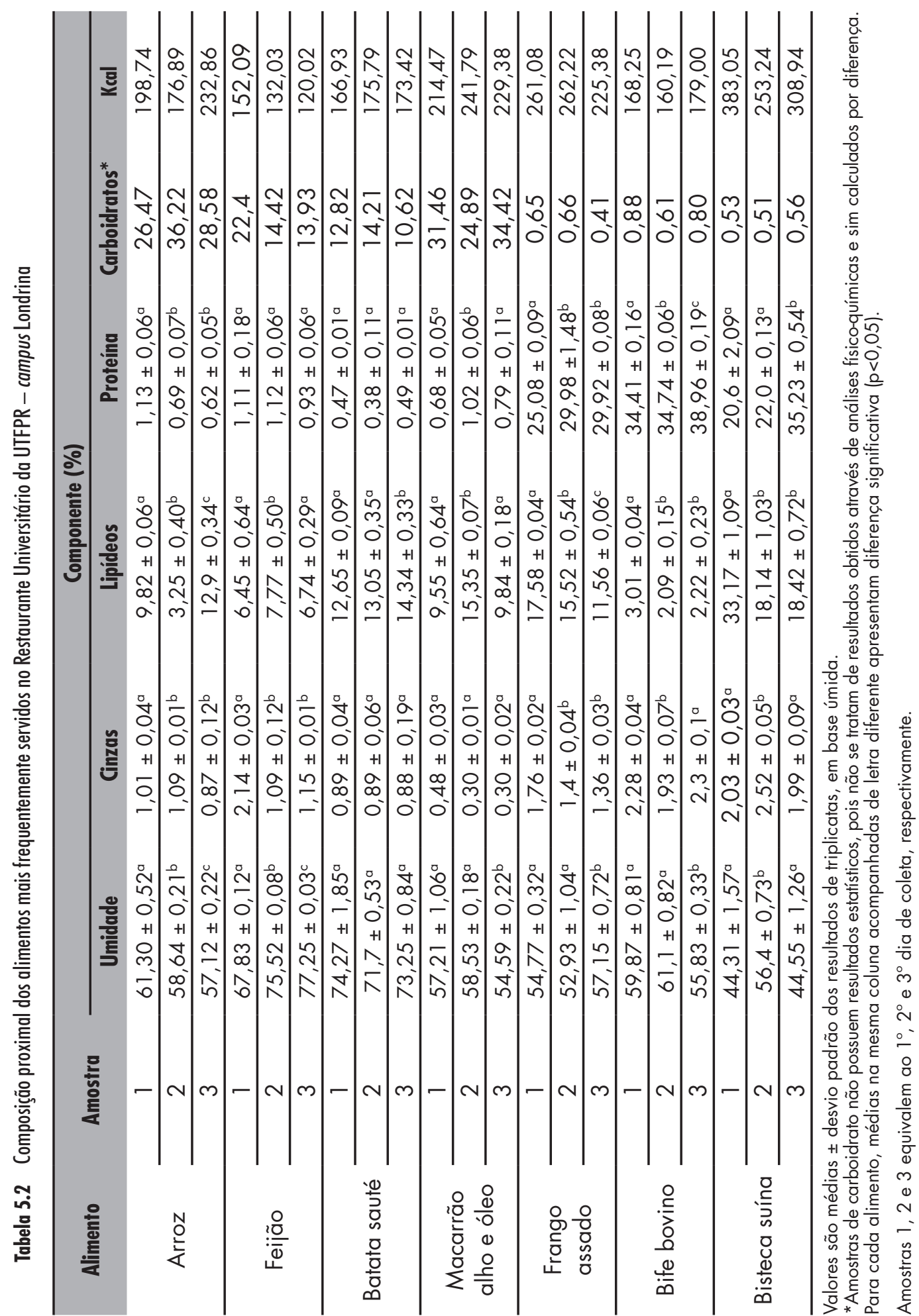


As três amostras de arroz apresentaram diferença significativa ao nível de $5 \%$ quanto à umidade, lipídios, carboidratos e calorias, não apresentando diferença apenas entre as amostras 2 e 3 para cinzas e proteínas. O maior valor energético obtido foi na amostra 3, devido à maior quantidade de lipídios encontrada.

As amostras de feijão diferiram entre si nos quesitos umidade e calorias, sendo que para proteína não houve diferença entre as três amostras. As amostras $2 \mathrm{e}$ 3 não apresentaram diferença significativa para cinzas e carboidratos, enquanto, para lipídios, apenas a amostra 2 se apresentou diferente das demais. A amostra 1 revelou valor energético mais elevado, provavelmente devido à menor taxa de umidade, o que eleva os outros parâmetros em comparação às demais amostras.

A umidade, teor de cinzas e proteína encontrados na batata sauté não apresentaram diferenças entre as diferentes amostras coletadas, e apenas a amostra 3 obteve diferença quanto ao teor de lipídios e carboidratos. No entanto, as três amostras resultaram em valores energéticos diferentes.

No macarrão, apenas o teor de cinzas não teve diferença entres os três preparos analisados, já para carboidratos e calorias os três diferiram. A amostra 3 apresentou menor teor de umidade, não havendo diferença entre as amostras 1 e 2 . Os teores de lipídios e proteínas não diferiram nas amostras 1 e 3 , sendo que o teor de lipídios da amostra 2 foi o mais elevado e, consequentemente, seu valor energético também.

Os três tipos de carne apresentaram teores de carboidratos semelhantes entre si. O frango assado obteve quantidades de lipídios diferentes nas três composições, umidade e valor energético com diferença significativa apenas na amostra 3, e cinzas e proteínas apenas na amostra 1.

O bife de carne bovina demonstrou menor umidade na amostra 3 , sendo que não houve diferença para cinzas de 1 e 3 , e para lipídios de 2 e 3 . No entanto, as três composições diferiram em proteína e valor energético.

A bisteca suína apresentou umidade e cinzas semelhantes nas amostras 1 e 3, e teores mais elevados desses na amostra 2. As amostras 2 e 3 não apresentaram diferença quanto ao teor de lipídios, a amostra 1 revelou maior conteúdo lipídico e assim, maior valor energético. A amostra 3 diferiu quanto ao teor proteico e todos os preparos diferiram quanto às calorias.

Realizou-se um levantamento entre as tabelas já existentes de composição proximal de alimentos, a fim de retirar destas tabelas os mesmos alimentos apresentados na tabela de composição proximal realizada neste trabalho para comparar seus resultados. Houve grande dificuldade para eleger estas tabelas de comparação, pois a maioria das tabelas encontradas não continham os alimentos de interesse ou suas preparações utilizavam ingredientes diferentes dos utilizados nas preparações do Restaurante Universitário.

Mesmo com algumas diferenças, que serão relatadas de acordo com cada tabela, foram selecionadas duas tabelas para comparação com os dados com a 
tabela deste trabalho: a tabela de composição proximal do Departamento de Agricultura dos Estados Unidos (USDA) e a Tabela Brasileira de Composição de Alimentos (TACO).

Comparando-se os resultados (Tabela 5.2) com as informações do Departamento de Agricultura dos Estados Unidos (Tabela 5.3), observa-se que o arroz apresentou um menor teor de umidade e teores bem mais elevados de lipídios, porém isso ocorre devido aos diferentes modos de preparo, pois o Restaurante Universitário utiliza óleo e temperos além da água e o sal, enquanto o USDA faz somente adição de água e sal. Com o aumento de lipídios, proporcionalmente os teores de proteína e carboidratos diminuem e o valor energético é maior.

Os dados fornecidos na Tabela 5.3 para o feijão são referentes ao "preparo caseiro", o que aproxima os lipídios e o valor energético dos valores encontrados neste trabalho. A quantidade de água adicionada, não informada em ambos, pode também ter aumentado a umidade e diminuído os carboidratos obtidos.

Tabela 5.3 Composição proximal de alimentos - Departamento de Agricultura dos Estados Unidos (Agricultural Research Service)

\begin{tabular}{cccccc}
\hline Componentes & \multicolumn{5}{c}{ Composição proximal (\%) } \\
\hline & Umidade & Lipídios & Proteínas & Carboidratos & Kcal \\
\hline Arroz & 68,44 & 0,28 & 2,69 & 28,17 & 130 \\
Feijão & 65,17 & 5,15 & 5,54 & 21,63 & 155 \\
Batata sauté & 47,25 & 12,52 & 3,00 & 35,11 & 265 \\
Macarrão* & 62,13 & 0,93 & 5,8 & 30,59 & 157 \\
Frango assado & 62,1 & 13,39 & 23,97 & 0 & 223 \\
Bife bovino & 48,37 & 24,6 & 23,9 & 0 & 324 \\
Bisteca suína & 61,36 & 10,57 & 27,97 & 0 & 255 \\
\hline
\end{tabular}

Fonte: USDA (2014)

*alimentos preparados com adição de sal e água somente.

$\mathrm{Na}$ batata sauté analisada neste trabalho, a umidade foi bem mais elevada e os carboidratos muito menores do que os encontrados na Tabela 5.3, porém os lipídios foram semelhantes. A quantia de água utilizada no preparo é provavelmente responsável por essa diferença, o que gerou também diferença no cálculo de carboidratos e posteriormente no valor energético.

O macarrão teve um desempenho similar ao da Tabela 5.3 quanto à umidade e carboidratos. Mas, assim como no arroz, o preparo de referência utiliza apenas sal e água, enquanto a formulação analisada continha alho e óleo, responsável pelo grande aumento lipídico, ocasionando maior valor energético. 
As três amostras de frango assado obtiveram teores de umidade mais baixos que os valores indicados na Tabela 5.3, porém a média do conteúdo lipídico se aproxima da tabela. Com essa diminuição de umidade, o percentual proteico resultante nas amostras foi mais elevado.

As quantidades de proteína do bife bovino foram mais elevadas na preparação do Restaurante Universitário, fato ocorrido pela menor umidade encontrada. O teor de lipídios foi bem menor que o da referência, o que possivelmente ocorreu devido às amostras utilizadas em ambos e à quantidade de gordura presente na amostra.

Da mesma forma, a bisteca suína pode ter apresentado grande diferença na umidade e lipídios devido à amostra selecionada. A média dos resultados de proteínas se aproxima da tabela de comparação, porém há grande diferença entre elas. Tais fatos estão ligados às diferentes carnes utilizadas nos dias de coleta e no modo de preparo não padronizado, que pode não ter sido o mesmo feito na pesquisa do USDA.

Tabela 5.4 Tabela Brasileira de Composição de Alimentos (TACO) - Composição de Alimentos por 100 gramas de parte comestível

\begin{tabular}{ccccccc}
\hline Componentes & \multicolumn{5}{c}{ Composição proximal (g/100 g) } \\
\hline & Umidade & Cinzas & Lipídeos & Proteina & Carboidratos & $\begin{array}{c}\text { Valor energético } \\
\text { Kcal }\end{array}$ \\
\hline Arroz* & 69,1 & 0,1 & 0,2 & 2,5 & 28,1 & 128 \\
Feijão* $^{*}$ & 80,4 & 0,7 & 0,5 & 4,8 & 13,6 & 76 \\
Batata sauté & 83,1 & 0,6 & 0,9 & 1,3 & 14,1 & 68 \\
$\begin{array}{c}\text { Frango } \\
\text { assado }\end{array}$ & 55,0 & 1,3 & 15,2 & 28,7 & 0 & 260 \\
$\begin{array}{c}\text { Bife bovino } \\
\text { Bisteca de } \\
\text { porco }\end{array}$ & 52,4 & 1,2 & 11,6 & 31,9 & 0 & 241 \\
\hline
\end{tabular}

Fonte: Tabela Brasileira de Composição de Alimentos -TACO (2011).

*alimentos preparados com adição de água somente.

Comparando-se os resultados com a Tabela Brasileira de Composição de Alimentos (TACO) (Tabela 5.4), observa-se que o arroz apresentou teores de umidade e proteína menores em relação a esta tabela, e valores de lipídeos e energético bem mais elevados, porém, é importante relatar que estas diferenças ocorreram possivelmente pelos diferentes modos de preparo, pois na tabela TACO o arroz foi preparado somente com a adição de água, enquanto o Restaurante Universitário utiliza óleo e temperos, além da água e o sal. Com o aumento destes lipídeos, consequentemente aumenta também o valor energético. Cinzas e carboidratos obtiveram resultados muito próximos aos indicados na tabela TACO. 
Quanto ao feijão, o resultado de umidade obtido foi um pouco menor e o resultado de proteína foi muito menor do que o da tabela TACO, podendo variar devido à proporção caldo/caroço colhida, antes da homogeneização da amostra, o que também explicaria a pequena elevação do teor de cinzas obtido em relação ao da tabela TACO. Já os resultados de lipídeos e valor energético obtidos foram muito elevados em relação aos da tabela TACO, porém, a preparação desta tabela foi realizada apenas com o feijão e a água, enquanto a do Restaurante Universitário utiliza óleo e temperos, além da água e o sal, resultando nestas elevações. O teor de carboidratos obtido foi maior de que o da tabela TACO, provavelmente devido à diferença nos teores de umidade.

A batata sauté da TACO é adicionada de margarina e salsinha, o que tornou menor a diferença entre os resultados de lipídeos, mas, ainda assim, os teores de lipídeos e valor energético da tabela obtida foram superiores aos da tabela TACO, possivelmente devido à variação de ingredientes e quantidades entre as preparações. Os teores de umidade e proteína foram menores em relação ao comparado, e o teor de carboidratos encontrado ficou bem próximo ao comparado.

A comparação entre o macarrão da TACO e a tabela do Restaurante Universitário não foi possível devido ao fato de que na TACO existe apenas a composição proximal para o macarrão cru, o que não torna interessante a comparação com os dados obtidos neste trabalho.

Quanto ao frango assado, o fato de as preparações serem muito semelhantes, à base da sobrecoxa do frango, assada com a pele, aproximou muito todos os resultados obtidos das tabelas de referência. A umidade e cinzas estão muito semelhantes à TACO, enquanto os teores de lipídeos, proteína, carboidratos e valor energético estão levemente abaixo dos encontrados na tabela TACO.

Os teores de umidade, cinzas e proteína do bife bovino obtidos foram superiores aos da tabela TACO, possivelmente devido à diferença de preparo, pois, na TACO, o bife (alcatra), foi grelhado, e no Restaurante Universitário, foi frito em chapa. Já o teor de lipídeos obtidos foi menor em relação ao comparado, possivelmente devido à diferença de amostra no momento da coleta.

Quanto à bisteca suína, nas duas tabelas a base das preparações foi fritura no óleo. O teor de umidade obtido e o informado pela TACO foram muito próximos, assim como os teores de carboidratos. Já os teores de cinzas foram elevados em relação à tabela, e o teor de proteína foi menor em relação à esta. Isso pode ter ocorrido por se tratar de amostras de diferentes qualidades. Os teores de lipídeos e valor energético obtidos foram superiores aos descritos na TACO, provavelmente devido à qualidade da matéria-prima e às diferentes quantidades de óleo utilizadas no momento da fritura das bistecas.

Foi possível verificar uma variação significativa na composição dos alimentos em dias diferentes, além de valores energéticos elevados, em geral. Este fato possivelmente 
ocorre devido à falta de padronização e falta de conscientização para preparação de alimentos de maneira saudável. É necessário rever o modo de preparo, os ingredientes e as quantidades dos mesmos, pois influenciam na saúde de quem os consome.

Ao fim do trabalho, foi elaborado um folheto contendo as informações nutricionais obtidas e as Informações Diárias Recomendadas (IDR), apresentadas na Figura 5.5, a fim de informar à comunidade universitária os resultados obtidos e possibilitar-lhes a comparação entre sua refeição e o que se deve consumir ao longo do dia.

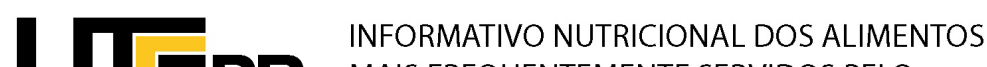

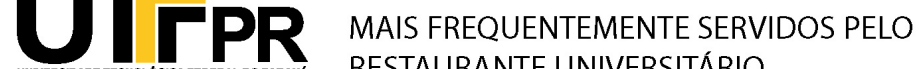

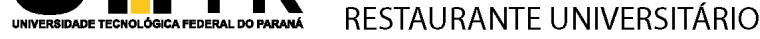

Fornecer uma alimentação balanceada e de qualidade em um Restaurante Universitário (RU) é fundamental à saúde dos consumidores. Esta deve satisfazer as necessidades nutricionais e energéticas, de acordo com a Ingestão Diária Recomendada (IDR). As tabelas a seguir representam os valores nutricionais dos alimentos mais frequentemente servidos pelo RU, e a tabela da ANVISA apresenta os valores da Ingestão Diária Recomendada.

INFORMAÇÃO NUTRICIONAL - RESTAURANTE UNIVERSITÁRIO UTFPR - CÂMPUS LONDRINA

\begin{tabular}{|c|c|c|c|c|c|}
\hline ALIMENTO & MEDIDAS RU & $\begin{array}{c}\text { VALOR } \\
\text { ENERGÉTICO (g) }\end{array}$ & CARBOIDRATOS (g) & PROTEÍNAS (g) & LIPÍDEOS (g) \\
\hline ARROZ & $\begin{array}{l}2 \text { COLHERES } \\
\text { RASAS }(100 \mathrm{~g})\end{array}$ & 202,59 & 30,36 & 0,81 & 8,66 \\
\hline FEIJÃO & $\begin{array}{c}1 / 2 \text { CONCHA } \\
(100 \mathrm{~g})\end{array}$ & 134,71 & 16,91 & 1,05 & 6,98 \\
\hline BATATA SOUTÉ & $\begin{array}{l}1 \text { COLHER } \\
(100 \mathrm{~g})\end{array}$ & 172,04 & 12,53 & 0,44 & 13,34 \\
\hline $\begin{array}{l}\text { MACARRÃO } \\
\text { ALHO E ÓLEO }\end{array}$ & $\begin{array}{l}1 \text { COLHER } \\
\text { RASA }(100 \mathrm{~g})\end{array}$ & 228,55 & 30,25 & 0,83 & 11,58 \\
\hline $\begin{array}{l}\text { FRANGO } \\
\text { ASSADO }\end{array}$ & $\begin{array}{l}1 \text { UNIDADE } \\
\text { MÉDIA (100g) }\end{array}$ & 249,56 & 0,58 & 28,33 & 14,88 \\
\hline BIFE BOVINO & $\begin{array}{l}1 \text { UNIDADE } \\
\text { MÉDIA (100g) }\end{array}$ & 169,15 & 0,77 & 36,04 & 2,44 \\
\hline BISTECA SUÍNA & $\begin{array}{l}\text { 1 UNIDADE } \\
\text { MÉDIA (100g) }\end{array}$ & 315,08 & 0,54 & 25,94 & 23,24 \\
\hline
\end{tabular}

ANVISA - Nutrientes de declaração obrigatória Ingestão Diária Recomendada (IDR) para um adulto saudável

\begin{tabular}{|c|c|}
\hline Nutrientes & \\
\hline Valor Energético & $2000 \mathrm{kcal}$ \\
\hline Carboidratos & $300 \mathrm{~g}$ \\
\hline Proteínas & $75 g$ \\
\hline Gorduras Totais & $55 g$ \\
\hline Gorduras Saturadas & $22 \mathrm{~g}$ \\
\hline Fibra Alimentar & $25 g$ \\
\hline Sódio & $2400 \mathrm{mg}$ \\
\hline
\end{tabular}




\section{CONCLUSÃO}

Com base no levantamento bibliográfico, na composição proximal obtida por meio das análises realizadas nos alimentos mais frequentemente servidos pelo Restaurante Universitário da Universidade Tecnológica Federal do Paraná - campus Londrina e no cálculo do valor energético, foi possível constatar uma variação expressiva na composição dos alimentos em dias diferentes, o que indica a falta de padronização e os elevados teores energéticos na maioria das preparações. Isso demonstra a necessidade de rever o modo de preparo, os ingredientes e as quantidades utilizados nas preparações dos alimentos, a fim de fornecer à comunidade acadêmica uma alimentação saudável e adequada quanto ao aporte de seus nutrientes.

\section{REFERÊNCIAS}

AKUTSU, R. C. et al. A ficha técnica de preparação como instrumento de qualidade na produção de refeições. Rev. Nutr., Campinas, v. 18, n. 2, p. 277-279, mar./ abr., 2005.

AOAC - Association of Official Analytical Chemist. Official Methods of Analysis. v. 2, 16.ed., 1995.

BEEFPOINT. USDA lança nova pirâmide alimentar. 2005. Disponível em: <http:// www.beefpoint.com.br/cadeia-produtiva/carne-saude/usda-lanca-nova-piramidealimentar-23478/>. Acesso em: 10 jul. 2014.

BORGES, C. M. Hábitos alimentares dos estudantes universitários: um estudo qualitativo. In: VII SEMEAD, Campo Grande, MS, 2013.

BRASIL. Ministério da Saúde. Resolução RDC n 360, de 23 de dezembro de 2003. Regulamento Técnico sobre rotulagem nutricional de alimentos embalados. Diário Oficial da União, Brasília, DF, 26 de dezembro de 2003.

. Ministério da Saúde. Resolução RDC nº 269, de 22 de setembro de 2005.

Regulamento Técnico sobre a Ingestão Diária Recomendada (IDR) de Proteína, Vitaminas e Minerais. Diário Oficial da União, Brasília, DF, 23 set. 2005.

Ministério da Saúde. Secretaria de Atenção à Saúde - Departamento de Atenção Básica. Guia alimentar para a população brasileira: promovendo a alimentação saudável. Brasília: Ministério da Saúde, 2006.

. Ministério da Saúde. Secretaria de Atenção à Saúde Saúde - Departamento de Atenção Básica. Guia alimentar para a população brasileira: promovendo a alimentação saudável. Brasília: Ministério da Saúde, 2008.

. Ministério da Saúde. Resolução RDC n 54, de 12 de novembro de 2012. Regulamento Técnico referente à Informação Nutricional Complementar. Diário Oficial da União, Brasília, DF, 12 nov. 2012.

FAUSTO, M. A. et al. Determinação do perfil dos usuários e da composição nutricional da alimentação oferecida no Restaurante Universitário da Universidade Estadual Paulista, Araraquara, Brasil. Rev. Nutr., Campinas, v. 14, n. 3, p. 171-176, set./dez., 2001. 


\section{FOSS. ANÁLISES QUÍMICAS - EXTRAÇÃO DE SOLVENTES COM SISTEMA}

SOXTEC ${ }^{\text {TM }}$. Disponível em: < http://www.foss-analytical.com.br/industry-solution/ chemical-analysis/solvent-extraction> Acesso em: 12 jul. 2014.

GONDIM, J. A. M. Composição centesimal e de minerais em cascas de frutas. Ciênc. Tecnol. Aliment., Campinas, v. 25, n. 4, p. 825-827, out.-dez. 2005.

IAL - INSTITUTO ADOLFO LUTZ. Métodos físico-químicos para análise de alimentos. 1. ed. digital. São Paulo: Instituto Adolfo Lutz, 2008.

KARAM, A. P. G.; NISHIYAMA, M. F. Implantação de Fichas Técnicas de Preparo na Cozinha Dietética de um Hospital na cidade de Foz do Iguaçu, Paraná. In: Seminário Científico de Nutrição, 1, 2009. Foz do Iguaçu: Faculdade das Américas, 2009. Disponível em: <http://www.uniamerica.br/site/revista/index.php/secnutri/article/ view/86/76>. Acesso em: 8 jun. 2014.

NEVES, M. F.; CHADDAD, F. R.; LAZZARINI, S. G. Gestão de negócios em Alimentos. São Paulo: Pioneira Thomson Learning, 2003.

OLIVEIRA, A. F.; ROMAN, J. A. Nutrição para tecnologia e engenharia de alimentos. Curitiba: CRV, 2013.

OLIVEIRA, R. B.; GUAGLIANONI, D. G.; DEMONTE, A. Perfil do usuário, composição e adequação nutricional do cardápio oferecido em um Restaurante Universitário. Alimentos e Nutrição, Araraquara, v. 16, n. 4, p. 397-401, out./dez. 2005. PARK, K. J.; ANTONIO, G. C. Análises de Materiais Biológicos. Disponível em: <http:// www.feagri.unicamp.br/ctea/manuais/analise_matbiologico.pdf>. Acesso em: 3 ago. 2014. PHILIPPI, S. T.; LATTERZA, A. R.; CRUZ, A. T. R.; RIBEIRO, L. C. Pirâmide Alimentar Adaptada: Guia para a escolha dos alimentos. Revista de Nutrição, Campinas, v. 12, n. 1, p. 65-80, jan./abr. 1999.

PINHEIRO, A. R. O. A alimentação saudável e a promoção de saúde no contexto da segurança alimentar e nutricional. Saúde em Debate, Rio de Janeiro, v. 29, n. 70, p. 125 139, maio/ago. 2005.

PROAD - Pró-Reitoria de Administração, UFPA. Restaurantes Universitários, 2013. Disponível em: <http://proad.ufpa.br/v2/index.php?option=com_content\&view=article \&id=25\&Itemid=20>. Acesso em: 6 ago. 2013.

ROCHA, M.S.D. Entrevista: Histórico Restaurante La Francine's. Universidade Tecnológica Federal do Paraná. Londrina, 7 jun. 2014.

TACO. Tabela Brasileira De Composição De Alimentos. Versão 2. 2. ed. Campinas: UNICAMP, 2011. Disponível em: <http://www.unicamp.br/nepa/taco/contar/taco_ versao2.pdf>. Acesso em: 10 jul. 2014.

USDA - UNITED STATES DEPARTAMENT OF AGRICULTURE. Choose My Plate. 2011. Disponível em: <http://www.choosemyplate.gov/about.html>. Acesso em: 10 jul. 2014.

UTFPR - Universidade Tecnológica Federal do Paraná - campus Londrina. Apresentação do Campus. Disponível em: <http://www.utfpr.edu.br/londrina/ocampus>. Acesso em: 11 jun. 2014.

VAZ, J. S. et al. Ácidos graxos como marcadores biológicos da ingestão de gorduras.

Rev. Nutri., Campinas, v. 19, n. 4, p. 489-500, jul./ago. 2006. 
